\title{
A TOOTH TATTOO WITH A PURPOSE: AN INNOVATIVE APPROACH
}

Neetu Kharat ${ }^{1}$, Anuroop Singhai ${ }^{2}$, Prasant M.C ${ }^{3}$, Ashishkumar K. Patil ${ }^{4}$, Fareedi Mukram Ali ${ }^{5}$

\section{HOW TO CITE THIS ARTICLE:}

Neetu Kharat, Anuroop Singhai, Prasant M.C, Ashishkumar K. Patil, Fareedi Mukram Ali. "A Tooth Tattoo with a purpose: An Innovative Approach". Journal of Evolution of Medical and Dental Sciences 2014; Vol. 3, Issue 04, January 27; Page: 921-925, D0I:10.14260/jemds/2014/1924

ABSTRACT: Skin is not the only place that can be decorated with a tattoo. You can decorate your tooth with amazing tattoos. Tooth tattoos and tooth jewels have become one of the hottest fashion trends, and a very popular arrival in cosmetic dentistry. But won't it be a boon if it had some preventive or medicinal value. Yes tooth tattoos can act as indicators of once illness. These tiny electronic sensors can diagnose illnesses by 'tasting' your breath. This paper is an insight into how a tooth tattoos can pick up early warning signs of sickness or infection by bacteria in people's breath.

KEYWORDS: Dental tattoo, graphene, sensor, Velcro.

INTRODUCTION: The concept of decorating or enhancing your teeth is actually quite ancient. In both China and Japan, women at one point stained their teeth black as part of their beauty regimens and in many cultures teeth were bordered in gold or replaced as a status symbol. Gold teeth were and are especially common in Latin America and the Caucasus. Dental tattoos are not new: it started in the west about 8-10 years ago when hippo singers and rappers started spotting them in their music videos and youngsters started aping them.1,2,3

Tooth tattoos are a new range in body art. Custom hand painted artwork is placed onto one's tooth. Typically tooth tattoos are applied to a replacement crown before it is inserted into one's mouth, although the process is also possible with an intentionally removed tooth. This term is also used for temporary decals and stains used to decorate the teeth. Dental tattoos can potentially be applied to any tooth, and they run a wide gamut of styles, colors and designs. [Fig-1]

Procedure to Make Dental Tattoos: Dental tattoos are usually applied by the dental lab which makes the crowns ${ }^{4}$. After a dentist takes a mould and confirms that it is correctly sized for the tooth, he or she sends it to a lab to be manufactured into a crown, or produces the crowns in-house, depending on personal preference. If the customer wants a dental tattoo, the mould may be sent to a lab which specializes in such things, and a skilled artist typically does the tattoo work, carefully painting a miniature design onto the tooth before it is sealed.5, 6

Types of Dental Tattoos: Dental tattoos can either be temporary or permanent ${ }^{1}$. In case of temporary tattoos, often termed "gnasher tats"7designs are in the form of templates that are stuck on the teeth. Various kinds of designs are available. You can also get a custom-made design in a dental laboratory, which your dentist can then stick on your teeth. Permanent tattoos are drilled on the teeth. Once done you cannot get them removed. While sticking a temporary tattoo takes just 1520 minutes, drilling permanent tattoos can take hours depending on the design. Usually the preferred areas for dental tattoos are the upper lateral incisors, upper canine, premolars and molars. Animal shapes are also quite popular. Other designs that are usually preferred are of name initials, heart and arrow, musical symbols, bull, Mickey Mouse, arrow, sign of victory and lips. 
Future Prospects: In our inked up future, the science of dental tattooing has plenty in store. In our near future you imagine soon vibrating tattoos will buzz when your phone rings, and change color when your blood sugar is low. A new kind of sensor made of grapheme would be able to tell you when you're ill, and even possibly what's ailing you--all from the bacteria on your breath. The antenna coil will transmit the signal and it would not need a battery ${ }^{8}$. A bonus, it won't even hurt to put them on. Mike McAlpine, at Princeton, a pioneer in research regarding graphene, believes that these sensors could be used to determine whether a wound has become infected, or in hospitals where patients with weakened immune systems are extra vulnerable to bacteria. In a test conducted with these grapheme sensors implanted on a cow's tooth the sensors successfully picked up the molecules of bacteria present in the student breath ${ }^{9}$ (Fig.No. 2).

Other applications of graphene sensors can be their use in testing the viability of food. The sensors can be used in hospitals, where infections of the antibacterial resistant superbug MRSA linger undetected on IV bags, shower curtains, and countless other surfaces ${ }^{10}$.

Structure of tooth tattoo with grapheme: The basic structure is a remote chemical sensor with graphene, a one-atom-thick layer of carbon, which is very sticky and has a super-sensitive surface. Next, peptides (a sequence of amino acids) are planted onto the surface of graphene. These peptides have a dual function one to stick to the graphene and secondly to detect bacteria at the single cell level. These dual function peptides are a combination of a peptide rich in "aromatic residues," which are apparently sticky, and with one that is isolated from a tropical frog which is super sensitive to three specific bacteria. A RFID (Radio frequency identification) is incorporated into the sensor to communicate alerts about an infection. These graphene sensors are supported on a silk film and implanted onto a surface. This silk film made of proteins later dissolve away, leaving the graphene sensor painlessly pasted into place (Fig No.3). These sensors can detect bacteria individually picking them up like Velcro. McAlpine is currently planning to license and commercialize this device. ${ }^{11}$

Cost of Dental Tattoos: The price of the procedure varies greatly, depending on complexity of the tattoo design, as well as the nature of the dental work being completed. For a basic design one may be required to shell out Rs.800. As the design becomes complex it may cost anywhere between Rs.10, 000 and Rs.15, 000.

Oral Hygiene Status with the use of Dental Tattoos: Though there are no documented side effects, but it depends on a person's oral and dental hygiene. If a person is lacking hygiene, then there could be cavities - but this can happen even without a tattoo.

Merits and Demerits of Dental Tattoos: The prime advantage of tooth tattoo is that the procedure is painless. The tattoos can easily be removed in five minutes in the dentist's office with just a little grinding with a rubber wheel. The major disadvantage is the possibility of plaque build-up around the tattoo, causing an increasing chance of tooth decay. But with good oral hygiene, this can be avoided. Further dental tattoos sometimes get abraded with time and needs to be replaced. Moreover unnecessary removal of tooth structure weakens the tooth which compromises the longevity of the tooth. Also in their present form, the sensors are too big to be practical. 
The major challenge is getting the antenna that transmits the data small enough to be used on a human (instead of a cow's) tooth. The researchers say they also need to better understand how long the adhesion between the enamel and graphene sensor will last, not to mention how well the system will weather the storm of the mouth -- from chewing to brushing ${ }^{12}$.

CONCLUSION: Normally this artwork is created on the back teeth, the molars or bicuspids. Most people prefer having it on the cheek side of the tooth, some on the tongue side. They are seen only when the person that has one wants to share what they have, by pulling their cheek out so it could be seen ${ }^{8}$. This artistic medical boom is still in its primitive form and needs lot more research and advancement. This imagination of vibrating, beautiful tattoos which can pick up bacteria to diagnose disease is soon going to not only revolutionize dentistry but also the medical profession. Thus it would be apt to call these tattoos a tattoo with a purpose.
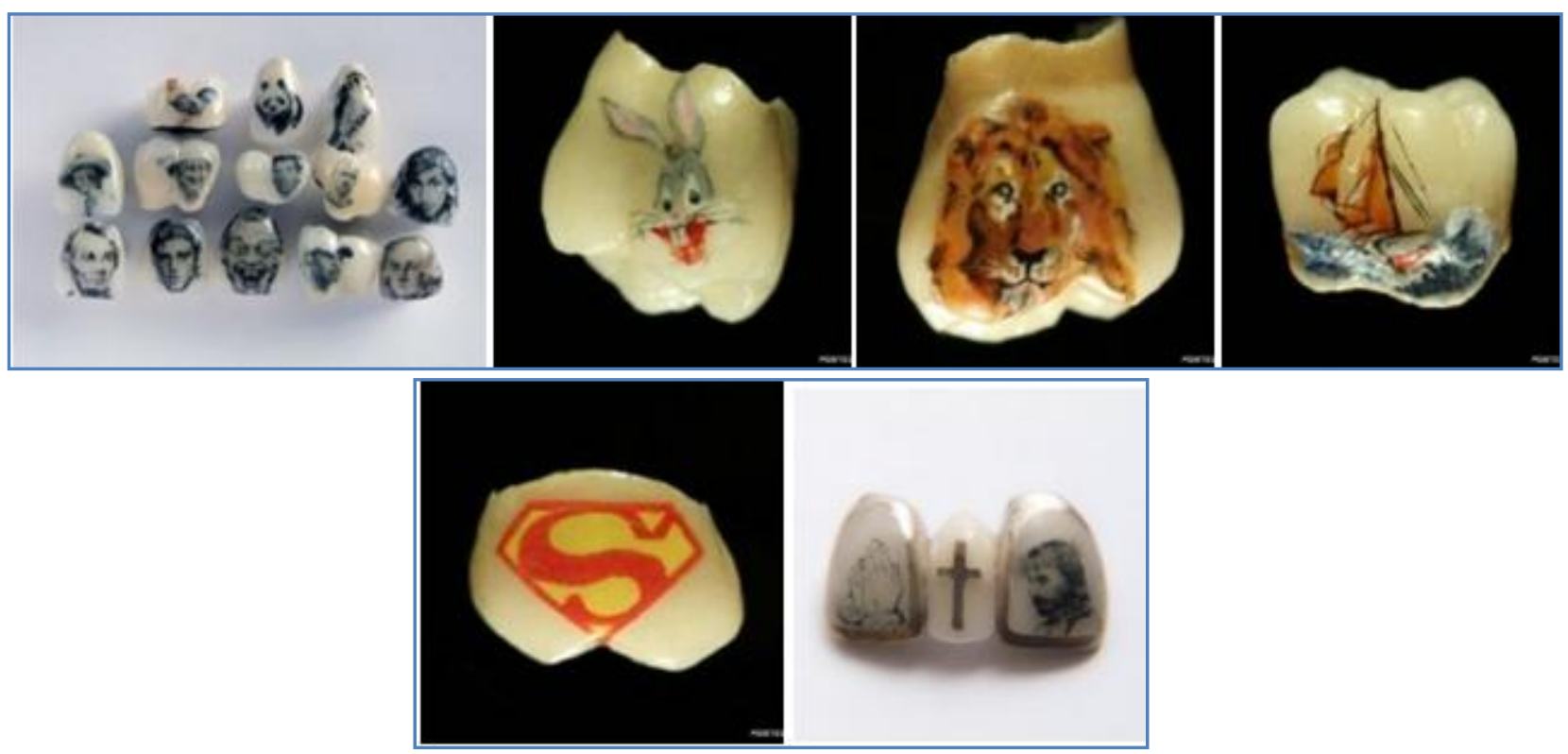

\section{Fig. No. 1: STYLES, COLORS AND DESIGNS OF TOOTH TATTOOS}

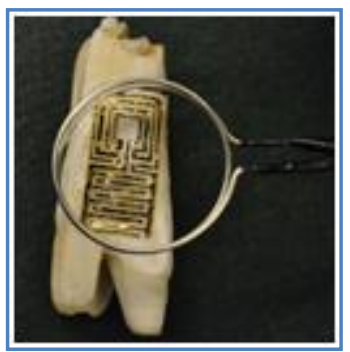

Fig. No. 2: On a cow's tooth, the sensor can detect bacteria and send a signal to a nearby receiver.

\section{(Credit: Michael McAlpine/Princeton University)}




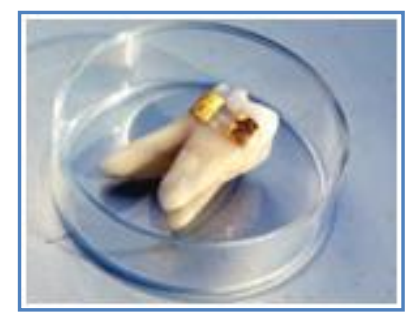

\section{Fig. No. 3: GRAPHENE SENSOR PASTED INTO PLACE}

Conflict of interest: none declared.

\section{REFERENCES:}

1. http://www.identalhub.com/dental-what-aredental-tattoos-801.aspx;

2. http://www.diva.com/news-style-beautybeautytrend-get-a-dental-tattoo4711;

3. http://www.newsonlive.mywebdunia.com/20110 628teeth-tattoo-in-fashion-now.html

4. http://www.dentalblog.priyakanwar.com/201109tattooth-tooth-tattoos-latest-trend.html

5. http://www.squido.com/toothtattoo/design

6. http://www.toothartst.com

7. http://articles.timesofindia.indiatimes.com/2012-08-29/trends/29733472_1_temporarytattoos-dental-college-dental-hygiene

8. http://articles.timesofindia.indiatimes.com/2012-06-09/science/32140014_1_sensor-toothgraphene

9. http://www.dailymail.co.uk/sciencetech/article-2124109/Could-ultra-sensor-teeth-save-lifeNew-electronic-tooth-tattoos-diagnose-illnesses-tasting-breath.html

10. http://www.fastcoexist.com/1679583/tooth-tattoos-will-tell-when-youre-ill

11. http://gizmodo.com/5897600/tooth-tattoo-diagnoses-illness-and-alerts-doctors

12. http://news.cnet.com/8301-11386_3-57448666-76/wireless-tooth-tattoo-can-detect-badbacteria/

13. Garg K, Chawla PS, Singh G. Tattooth: tooth tattoo, a new rage in body art. International Journal of Advanced Biotechnology and Research. 2012: 3 (1); 498-501. 


\section{AUTHORS:}

1. Neetu Kharat

2. Anuroop Singhai

3. Prasant M.C.

4. Ashishkumar K. Patil

5. Fareedi Mukram Ali

\section{PARTICULARS OF CONTRIBUTORS:}

1. Senior Lecturer, Department of Conservative Dentistry \& Endodontics, RKDF Dental College and Research Centre, NH-12, Hoshangabad Road, Misrod, Bhopal.

2. Senior Lecturer, Department of Oral \& Maxillofacial Surgery, RKDF Dental College and Research Centre, NH-12, Hoshangabad Road, Misrod, Bhopal.

3. Dean \& HOD, Department of Oral \& Maxillofacial Surgery, RKDF Dental College, Bhopal.
4. Senior Lecturer, Department of Conservative Dentistry \& Endodontics, SMBT Dental College, Sangamner.

5. Reader, Department of Oral \& Maxillofacial Surgery, SMBT Dental College, Sangamner.

\section{NAME ADDRESS EMAIL ID OF THE CORRESPONDING AUTHOR:}

Dr. Anuroop Singhai, Senior Lecturer,

Department of Oral \& Maxillofacial Surgery, RKDF Dental College and Research Centre, NH-12, Hoshangabad Road, Misrod, Bhopal. E-mail: anuroopsinghai@gmail.com

Date of Submission: 13/12/2013.

Date of Peer Review: 14/12/2013.

Date of Acceptance: 27/12/2013.

Date of Publishing: 23/01/2014 